\title{
Editorial:
}

\section{A new inborn error of metabolism}

Many inherited metabolic diseases have a recognizable manifestation in the eye. The reader may like to jot down those that come to mind-there are at least thirty. Several are associated with cataracts, others with corneal clouding, retinal pigmentation, and four with a cherry-red macular spot, and there are three causes of ectopia lentis.

For the present purpose the term "inherited metabolic disease" is confined to those diseases primarily due to an enzyme deficiency and all are inherited by a recessive or sexlinked mechanism. There are no dominantly inherited diseases that are primarily due to an enzyme deficiency and in the many dominantly inherited eye disorders the clinical chemist is unlikely to be able to help with either diagnosis or further classification of the disorder. Thus, such diseases as diabetes and nephrosis with an established biochemical association are not included in the present discussion.

Ophthalmologists need feel no embarrassment from any lack of knowledge of this group of diseases (unless they scored less than five in the test above) as the subject is not amenable to the usual methods of acquiring clinical experience-it needs a more mechanical system of information retrieval. The paper Management of Inherited Metabolic Disease (Raine, I972) attempts to provide this in a convenient form and where it falls short the clinician should expect to refer to such key reference books as McKusick (I97I), Geeraets (I969), and Stanbury, Wyngaarden, and Fredrickson (1972) for the information he needs.

If, after this, the Ophthalmologist is moved to seek biochemical help, he will immediately encounter a language barrier. The use of eponyms and unfamiliar technical jargon by all who work in eye departments is quite forbidding, and the need to overcome this barrier to communication should be recognized at an early stage.

Once contact is established, however, the laboratory can offer quite a lot of help in searching for metabolic causes. Amino-acids and sugars are not the only areas of metabolism that may be defective and all laboratories should be able to perform the scheme of analysis of blood and urine outlined by Berry, Leonard, Peters, Granger, and Chunekamrai ( 1968 ) which, if preceded by the even simpler urine tests detailed by Perry, Hansen, and MacDougall (1966) and Buist (r968), will give information concerning phenols, sulphur compounds, reducing substances, protein, tyrosine derivatives, amino and keto acids, acid mucopolysaccharides (now called glycosaminoglycans), and some other compounds.

Encouragement to pursue recessive and sex-linked disorders so far should be afforded by the report on page 3 of this issue which shows that gyrate atrophy of the choroid and retina is associated with very high concentrations of ornithine in the plasma.

The author gives no indication of what led to this discovery in this or earlier papers, unless it was a chance finding in the boy with a large lysine-ornithine spot on high-voltage electrophoresis of his urine. Even this might have passed unregarded, for the presence of notable amounts of lysine with cystine is a feature of the heterozygous state of one form of cystinuria. This is not an uncommon finding and, by itself, is not associated with disease. However, gyrate optic atrophy had already been shown to be inherited in an autosomal recessive fashion and as it was, therefore, a strong candidate for inclusion in the group of enzyme deficiencies no biochemical clue could be overlooked. 
Having established that the spot was ornithine and not lysine (the two run together and are poorly separated), the investigators were then confronted by another general principle, that there are likely to be several causes of the same biochemical abnormality. This may be because several different enzymes in a metabolic pathway can, if deficient, lead to the same biochemical abnormality: or, as is now accepted, there may be several different abnormalities of the same enzyme protein. Compare the many different abnormalities of haemoglobin, all due to the substitution of a specific amino-acid in the chain by another not normally present. Enzyme deficiencies are due to similar substitutions and if these involve the active site of the enzyme, function will be interfered with. Thus there are more than seventy abnormal forms of glucose-6-phosphate dehydrogenase (G6PD). Galactosaemia is associated with two different abnormalities of galactose-I-phosphate uridyl transferase, but only one form is severe enough to be associated with cataracts. On the other hand, galactokinase deficiency is associated with cataracts and, in terms of simple screening tests, gives results similar to those found in cases of galactosaemia.

So with ornithine, and Dr. Takki discusses two reports of ornithinaemia which he feels are different from the type he originally discovered. This may indeed be so and only a study of the enzyme itself in these several diseases will resolve the question. However, one of the clinical reasons given for his supposition does not carry as much weight as might appear at first sight. It is that one form of ornithinaemia is associated with mental subnormality, and in no case was this associated with optic atrophy in the present series. Because many of the inherited metabolic diseases first discovered were associated with mental subnormality, it became customary to search for others among patients who were similarly affected. Thus a number of genetically determined urinary abnormalities have been wrongly associated with subnormal mentality and only after some years of further study have sufficient examples of the chemical abnormality been found in normal subjects to establish the original association as a coincidence of two disorders. Thus cystathioninuria, iminoglycinuria (the urinary excretion of glycine, proline, and hydroxyproline), and possibly prolinaemia type I, are no longer regarded as diseases, and the syndrome of hiatus hernia, mental retardation, and sucrosuria is now known to be spurious.

None of these remarks is intended to criticise Dr. Takki's study but rather to highlight the difficulties of interpretation in his or any similar investigation. It is probable that subsequent study will establish the association of this striking degree of ornithinaemia with the pathological state. Indeed, where pathology is caused by an enzymatic abnormality, the biochemical manifestations are usually dramatic. However, only when the dramatic examples have been elucidated will the more subtle be fully explored.

\section{References}

berry, H. K., Leonard, c., peters, h., granger, m., and chunekamrai, n. (ig68) Clin. Chem., r4, I 033

BUIST, N. R. M. (I968) Brit. med. J., 2, 745

GeEraets, W. J. (I969) “Ocular Syndromes", 2nd ed. Lea and Febiger, Philadelphia

MCKusick, v. A. (I97 I) "Mendelian Inheritance in Man”, 3rd ed. Johns Hopkins Press, Baltimore perry, t. l., hansen, s., and macdougall, l. (ig66) Cianad. med. Ass. J., 95, 89

RAINE, D. N. (I972) Brit. med. J., 2, 329

STANBURy, J. B., WYNGaARden, J. B., and FREDrickson, D. s. (I972) "The Metabolic Basis of

Inherited Disease", 3rd ed. McGraw-Hill, New York 